\title{
New strategies to overcome water limitation in cultivated maize: results from sub-surface irrigation and silicon fertilization
}

\author{
SinaBesharat ${ }^{\mathrm{a}}$ LúciaBarão $^{\text {bc }}$ CristinaCruz $^{\mathrm{b}}$ \\ ${ }^{a}$ Department of Water Engineering, Faculty of Agriculture, Urmia University, Urmia, 57153, Iran \\ ${ }^{\mathrm{b}}$ Center for Ecology, Evolution, and Environmental Changes (cE3c), University of Lisbon, Campo Grande, 1749-016, Lisbon, \\ Portugal \\ c Institute of Mediterranean Agricultural and Environmental Sciences (ICAAM), University of Évora, Núcleo da Mitra \\ Apartado, 94 7006-554, Évora, Portugal
}

Sina Besharat, Lúcia Barão, Cristina Cruz, New strategies to overcome water limitation in cultivated maize: Results from subsurface irrigation and silicon fertilization, Journal of Environmental Management, Volume 263, 2020, 110398, ISSN 03014797, https://doi.org/10.1016/j.jenvman.2020.110398.

\section{Abstract:}

The increasing growth of the world's population has established an unprecedented pressure in the availability of fresh water resources, with food production systems consuming over $70 \%$ of the world's fresh water withdrawals. Other pressures include climate change effects and the increasing number of semi-arid regions. The present challenges are therefore the maintenance of high production rates with fewer resources, especially in regions where water is becoming less accessible. In this study, we have tested the effect of sub-surface irrigation and silicon fertilization in maize growth with and without water limitation. These solutions have been suggested as effective in drought conditions but an overall study of their effects on the soil water balance and root length density is lacking. We have conducted a pot experiment with maize for 101 days where measurements in soil water content and root length were taken. Also, Hydrus 2-D was used to simulate the root water uptake and calculate the water balance. Results show that both sub-surface irrigation and silicon fertilization increase the root system by $21 \%$ and $34 \%$ respectively in water stress situation. Also, in the case of no water stress, silicon fertilization still induces an increase of $11 \%$ in the root development, showing that this solution has positive effects even when the crop is not hydrologically limited. Indeed the root water uptake was higher for the silicon treatment when no water limitation was present $(71.6 \mathrm{~L})$, compared to the sub-surface irrigation $(62.5 \mathrm{~L})$ and the control $(62.3 \mathrm{~L})$. While sub-surface irrigation generally decreased evaporation, the silicon treatment lowered drainage by promoting a better and more efficient root water uptake.

Keywords: Agriculture; Freshwater resources; Hydrus; Management; Root growth.

\section{Introduction}

Globally, water consumption for agriculture accounts for $70 \%$ of the total. Most are used for irrigation. The food demand will increase by $60 \%$ by 2050 , and this increase will require more arable land and more production (Boretti and Rosa, 2019). The increasing growth of the world's population has established an unprecedented pressure in the availability of fresh water resources, with food production systems consuming over 70\% of the world's fresh water withdrawals (Pimentel et al., 1995). Crops and animal feed production while essential to maintain the world's population food security, are high consumers of this essential resource (Craswell et al., 2007; Hoekstra and Mekonnen, 2012). Moreover, under climate change effects, crops will grow subjected to less available freshwater resources and more water stress limitations periods (Arnell, 1999; Milly et al., 2005; Oki and Kanae,2006). Also, the 
number of semi-arid regions is expected to increase, raising new difficulties to agriculture in these areas, where food production is critical (Ragab and Prudhomme, 2002).

The present challenges are therefore the maintenance of high production rates with fewer resources, especially in regions where water is becoming less accessible. As an example deficit irrigation (DI) has been developed as a water-saving irrigation strategy where crops receive less irrigation water during their growing season (Geerts and Raes, 2009). However, although adapting DI may be a rational decision under an existing water crisis it may lead to a significant yield loss (Payero et al., 2006) that may threaten food security. During recent decades, an efficient irrigation method named partial rootzone drying (PRD) has also been developed (Dry and Loveys, 1998). In this method, one-half of the root zone is irrigated while the other half is allowed to dry out. The irrigated and dry sides are periodically switched. It has been reported that this water-saving irrigation method can reduce irrigation amounts without reducing crop yield and hence can increase water and nutrient use efficiencies (Kang and Zhang, 2004; Karandish and Shahnazari, 2016; Shao et al., 2008). Other popular strategy is also the use of sub-surface irrigation, where water is provided directly in the root zone, thus diminishing the water loss through evaporation (Ayars et al., 1999). This management is especially interesting for areas where water availability is decreasing and the losses through evaporation are significant (DarziNaftchali and Shahnazari, 2014; Siyal and Skaggs, 2009). However, root distribution exerts strong influence on subsurface drip irrigation design and management practices, as water uptake by plant roots determines spatial and temporal patterns in soil water availability (Gärdenäs et al., 2005) and therefore the study of root growth patterns is crucial. Research from the past decades also shows that crops growing under water stress benefit from Silicon (Si) fertilization (Crusciol et al., 2009; Hattori et al., 2005; Saud et al., 2014). Si has gained significance in agriculture since its uptake by Si-accumulator crops, such as cereals, is shown to ameliorate metal toxicity (Adrees et al., 2015), increase resistance to pests and diseases (Rodgers-Gray and Shaw, 2004) and generally helps crops cope with limitation situations (Guntzer et al., 2011). However, the exact mechanisms by which Si influences the crop remains unclear as also the upscale of using Si fertilization as a water-saving strategy.

When evaluating different options suggested and/or developed to diminish water consumption by crops, it is often a problem to quantify the water movement in soil and the flow associated with root water uptake. The soil-plant system complexity and the time-dependency of the soil water content raises some uncertainty on the local measurements, while the use of empirical, analytical and numerical models remain as a valuable tool to assess the full water balance in a specific timeframe (Han et al., 2015; Kandelous and Šimůnek, 2010; Li et al., 2015). The ever increasing pace of computational power along with significant advances in numerical modelling of soil relationships enables the application of numerical vadose zone simulation models for analyses of micro-irrigation systems involving a wide range of crops (Hanson et al., 2006). 
In this study, we have conducted a greenhouse experiment with maize and used a numerical model to simulate water content in soil during the crop-growing period, in order to test the effects of: 1) subsurface irrigation and 2) Si fertilization, both in normal and stress water conditions. We have chosen these two water saving techniques since they show real potential to diminish the irrigation water required while being simple techniques that do not require expensive equipment. This is especially important for the development of semi-arid regions, where water saving represents an important environmental and economic gain. We have used maize, since it is one of the most produced crops in the world (Guntzer et al., 2011), an important crop in semi-arid regions, while is also an Si-accumulator crop (Hodson et al., 2005). The main goals are: (i) evaluate maize root water uptake and the water balance in normal and limited water conditions; (ii) evaluate root growth and calibrate numerical models with new parameters and; (iii) reflect on the possibility to use sub-surface irrigation or Si fertilization as a valid strategy towards freshwater saving strategies in agriculture.

\section{Materials and Methods}

\subsection{Greenhouse experiment}

Pot experiments were conducted at the greenhouse of the University of Lisbon ( $38.75 \mathrm{~N} 9.16 \mathrm{~W})$ located at $15 \mathrm{~m}$ above sea level, from June to September in 2017 (in a total of 101 days). Air temperature, dew point and humidity were recorded every 30 minutes.

Maize seeds were placed in water for two days and were then transferred to the soil-vermiculite matrix to allow germination during 14 days. Each seedling was then cultivated in a small container and moved to the greenhouse.

The greenhouse experiment included 56 pots (size: 20x40x60 cm). The majority of pots (48) contained soil mixed with vermiculite $(50 \% / 50 \%)$, but since this clay mineral is a source of Si (Schaetzl and Anderson, 2005), one of the treatments (8 pots) included soil but without the addition of vermiculite (100\% soil). Soil and vermiculite properties are shown in Table 1.

Each pot was fertilized with $10 \mathrm{~g}$ of an 8-15-15 N:P:K fertilizer. As top dressing nitrogen fertilization, $200 \mathrm{~kg} \mathrm{~N} / \mathrm{ha}$ was used as urea.

\subsection{Sub-surface irrigation and Si fertilization treatments}

Seven different treatments were considered. Sub-surface irrigation and Si fertilization was tested in pots where water irrigation provided was 100\% (SVSub100 and SVSi100) and 50\% (SVSub50 and SVSi50) and then compared to normal surface irrigation without Si fertilization for the same irrigation conditions 
1 (SV100 and SV50). The 100\% and 50\% of irrigation treatments correspond respectively to situations 2 of no water limitation and water limitation. The water limitation in literatures were arranged between $350 \%$ till 100\% full irrigation (Kanga, et al, 2000; Kresovi'ca, et al; 2016, Kresović, et al 2018), the most 4 literature were compered the water amount of irrigation effect on plant. References indicate that most

5

6

7

8 irrigation experiments designed at least 50\%. The plant cannot tolerate less than 50\% and the yield of the crop is drastically reduced. Therefore we select maximum and minimum deficit irrigation to find more effect and significant on plant physiology and water behavior on these conditions.. The $100 \%$ and $50 \%$ water condition were achieved with irrigation of $2 \mathrm{~L}$ and $1 \mathrm{~L}$ of water during the first 30 days and then 3 and $2 \mathrm{~L}$ for the remaining days, respectively. Irrigation occurred with an interval of 1 or 2 days, depending on daily water content measurements. The sub-surface treatment included the addition of water directly at the depth of $25 \mathrm{~cm}$ thus readily available for the roots, using a polyethylene tube previously incorporated in the pot. In the treatment with silicon, an earlier version of the PlusMaster fertilizer (adp-fertilizantes.pt) was added in a quantity of $10 \mathrm{~g}$ per pot, before the seedlings, since this is a silicon-based fertilizer. Each treatment set was replicate in 8 different pots, randomized during the experiment in the greenhouse.

\subsection{Soil and plant measurements}

Soil moisture was taken at 12 different points in each pot daily (6 depths 10, 20, 30, 40, 50, 60 and 2 distances from center 10, $20 \mathrm{~cm}$ ) using a WET sensor. . WET sensor checks water content by time domain reflectometry method (WET Sensor, Type HH2, Delta-T Device, Cambridge, UK).

Plant height was recorded in every pot 6 times during the experiment. By the end of the experiment, maize was harvested and the aboveground biomass was weighted fresh. Also, at four different times during the growth period (day 44, 68, 89 and 101), 2 pots from each treatment were cut and root density was assessed by dividing the soil in the pot in different cubes. For accuracy measurements of root density in soil layers, pots were cut in small soil cubes $(10 \times 10 \times 15 \mathrm{~cm})$ and then remove each cube. Cubes were used to have equality in all directions. Then, for each cube sampled, soil was washed, roots were removed and weighted.

\subsection{Water balance assessment using Hydrus}

The water balance was calculated by daily water content measurements data (WET sensor-Delta-T) and the amount of irrigation was measured during the growing season. Evaporation rates from soil surface and amount of drainage water were recorded in all pots. Based on these measurements, water balance was calculated. All these parameters were also simulated and compared using the Hydrus-2D Model. 
1 The most important issue was to calculate the root water uptake values in the pots, which were

2 determined based on water balance data.

3 The water balance achieved in each pot is a result of water sources and sinks (1), i.e. the water inputs 4 through irrigation $\left(\mathrm{W}_{\mathrm{i}}\right)$ and the water lost by evaporation $\left(\mathrm{W}_{\mathrm{e}}\right)$, transpiration from plants $\left(\mathrm{W}_{\mathrm{t}}\right)$ and 5 drained after leaching through soil $\left(\mathrm{W}_{\mathrm{d}}\right)$.

$6 \quad \frac{\Delta W}{\Delta T}=W_{i}-W_{e}-W_{t}-W_{d}$

7 To correctly estimate the water content variability and all these associated flows in the water balance

8 we used the Hydrus 2D in vertical plane model. The domain geometry set up was defined as $35 \mathrm{~cm}$ in 9 width and $60 \mathrm{~cm}$ in depth, with five soil layers: 0-20, 20-40, 40-60 cm. In all HYDRUS-2D simulations 10 we assumed that the soil is homogeneous. Therefore, the two-dimensional transport domain is rectangular. The soil water movement is calculated with Richards equation (Van Dam and Feddes, 2000) and the soil hydraulic properties were estimated with the van Genuchten-Mualem functions (Genuchten, 1980). Saturated water content $\left(\theta_{\mathrm{s}}\right)$ and saturated hydraulic conductivity (Ks) were measured values, whereas $\theta_{\mathrm{r}}$, and $\mathrm{n}$ were estimated via the Rosetta pedotransfer functions (Schaap, 2002) using a bulk density dataset and the particle size distribution. The spatial domain was discretized using triangular finite elements (FE). A time-variable boundary condition was used along the top boundary elements representing the irrigation and evaporation so that the total free drainage (unit gradient) boundary condition was applied along the bottom boundary, allowing for downward drainage and leaching. All other remaining boundaries were assigned a zero water flux condition. The remaining part of the left boundary was a zero-flux boundary both during and after the irrigation event. Initial conditions for all simulations were given in terms of constant water contents. The measured twodimensional soil moisture profile data after irrigation was used as initial condition.

The total volume of water removed from soil due to plant transpiration is assessed by calculating the root water uptake of maize in each grid cell for a certain time step (2):

$S_{\text {max }}(x, z, t)=\frac{\alpha(h) \times S_{t} \times T_{p}(t) \times R L D(x, z, t)}{\int_{0}^{X_{m}(t)} \int_{0}^{Z_{m}(t)} R L D(x, z, t) d x . d z}$

where $\mathrm{a}(\mathrm{h})$ is the soil water stress function, St is the length of the soil surface associated with transpiration $(\mathrm{cm})$; $\mathrm{Tp}(\mathrm{t})$ is the potential transpiration rate $\left(\mathrm{cm}\right.$ day $\left.{ }^{-1}\right) ; \mathrm{Xm}$ and $\mathrm{Zm}$ are the maximum rooting lengths in the $\mathrm{x}$ - and $\mathrm{z}$-directions $(\mathrm{cm})$, respectively; and $\operatorname{RLD}(\mathrm{x}, \mathrm{z}, \mathrm{t})$ is the root distribution function. The unit of root water uptake is $\mathrm{L}^{3} \mathrm{~L}^{-3} \mathrm{~T}^{-1}$ (Vrugt et al. 2001) so in some references the unit was showed by $\mathrm{T}^{-1}$ or Day ${ }^{-1}$ (Mohammadi et al, 2019). It means volume of water uptake per volume of soil per special time. 
1 The stress function, $\alpha(\mathrm{h})$ is calculated through the development of Feddes et al. (2001) the following

2 parameters: $P_{0}=-10 \mathrm{~cm}, P_{\text {opt }}=-25 \mathrm{~cm}, P_{2-1}=-200 \mathrm{~cm}, P_{2-2}=-600 \mathrm{~cm}, \mathrm{P} 3=-14,000 \mathrm{~cm}$.

3 The estimation of root length density (RLD) is calculated with the model of Vrugt et al. (2001) which

4 is as follows (3):

$5 \quad R L D(x, z, t)=\left[\frac{1-x}{X_{m}(t)}\right] \times\left[\frac{1-z}{Z_{m}(t)}\right] \times e^{-\left[\frac{P_{x}}{X_{m}(t)}\right] \times\left|x^{*}-x\right|-\left[\frac{P_{z}}{Z_{m}(t)}\right] \times\left|z^{*}-z\right|}$

6

7

where $\mathrm{P}_{\mathrm{x}}, \mathrm{P}_{\mathrm{z}}, \mathrm{x}^{*}(\mathrm{~cm})$, and $\mathrm{z}^{*}(\mathrm{~cm})$ are empirical parameters.

The empirical parameters used in the equation were calculated using the RLD measurements in the greenhouse experiment, using minirhizotrons. In each numerical simulation we assumed that the maximum rooting depth $\left(\mathrm{Z}_{\mathrm{m}}\right)$ and maximum root radial $\left(\mathrm{X}_{\mathrm{m}}\right)$ of maize was similar to 65 and $25 \mathrm{~cm}$, the boundary of our hypothetical soils. The root density distribution was fitted to deduce the root density function. In the inverse modeling stage of this study a total of 4 (e.g. Pz, z*, Px, x) root density parameters were identified simultaneously for HYDRUS model. Root density parameters were calibrated for all treatments. In this research, due to different irrigation and soil conditions, root density densities were obtained in different soil layers. However, the model could accurately simulate root density.

The model was also validated by comparing the soil water content (SWC) values estimated by the model and the ones measured in the greenhouse experiment in 101 days without changing the calibrated parameters. One-way analysis of variance (ANOVA) comparisons were made using the uni-variate general linear model (GLM) in SPSS Statistics 21.0, and the means were compared using least significant differences (LSD) after the ANOVA results were confirmed to be significant. The level of significance used for all statistical tests was $\mathrm{p} * 0.05$.

The following set of indicators was used to evaluate the agreement between the simulated results and the observed data for each treatment: root mean square error (RMSE) and error values for the root parameters (4) and (6) and RMSE and model efficiency (EF) for soil water content (4) and (5).

$R M S E=\left[\frac{\sum_{i=1}^{n}\left(P_{i}-O_{i}\right)^{2}}{n}\right]^{1 / 2}$

$E F=\frac{\sum_{i=1}^{n}\left(O_{i}-\bar{O}\right)^{2}-\sum_{i=1}^{n}\left(P_{i}-O_{i}\right)^{2}}{\sum_{i=1}^{n}\left(O_{i}-\bar{O}\right)^{2}}$

Error $=\frac{1}{N} \sum\left|\frac{O_{i}-P_{i}}{O_{i}}\right| \times 100$

Where $P_{i}$ are fitted values, $O_{i}$ the measured values and $n$ is the number of samples.

Error values and mean squared error are acceptable for use in this model (Gong et al., 2006; Vrugt et al., 2001). For good model performance, values of RMSE should be close to 0; high values of RMSE 
indicate poor model performance (Kandelous et al, 2011; Karandish and Simunek, 2016; Ursulino et al, 2019). The EF compares the deviations between predicted and observed values to the variance of the observed values. Values for EF can be positive or negative with a maximum value of 1 . The efficiency factor is a dimensionless statistic which directly relates predictions to observed data. Two time series are compared. EF is an overall measure of similarity between fitted and observed values. Any model giving a negative value cannot be recommended, whereas values close to one indicate a 'near-perfect' fit (Ursulino et al, 2019).

\section{Results}

\subsection{Measurements in the greenhouse}

\subsubsection{Fresh biomass and plant height}

Plant height recorded in the greenhouse varied between $72-120 \mathrm{~cm}$ in day 37 and $260-320 \mathrm{~cm}$ in day 101 when the maize was harvested (Figure 1). During the first 86 days there was no significant difference in plant height registered in the different treatments $(\mathrm{p}<0.05)$. However, plant height registered in day 87 was significantly different between treatments, specifically between treatment SVSub50 and SVSi100 ( $\mathrm{p}=0.03$ ). From this day on, there was no statistical significance on the treatments, also due to the fact that a lower number of pots remained available for measurements before maize was harvested. By the end of the experiment (day 100), there was a distinction between treatment Soil100, SVSi100 and SVSi50, which registered the highest values (300-312 cm), as opposed to SV100, SV50, SVSub100 and SVSub50 $(265-282 \mathrm{~cm})$.

Fresh biomass was measured after maize harvest in the two remaining pots that were not used to assess the root length density (Figure 2). Results show that treatments with $100 \%$ irrigation always returned higher amount of biomass $(\mathrm{S} 100=3335 \pm 77.8 \mathrm{~g} ; \mathrm{SV} 100=2995 \pm 148.5 ; \mathrm{SVSub} 100=3080 \pm 141.4 \mathrm{~g}$; SVSi100=3245 $\pm 134.4 \mathrm{~g}$ ) when compared to treatments where water was limited (SV50 = $2380 \mathrm{~g}$; SVSub50=2415 $\pm 91.9 \mathrm{~g} ;$ SVSi50=2820 $\pm 99 \mathrm{~g}$ ). Within the limitation the treatment where sub-surface irrigation was used returned higher biomass that the regular control treatment but the best result was obtained when silicon fertilizer was applied.

3.1.2 Crop yield biomass was analyzed among treatments, the results show that the fresh biomass in SVSi100 was increased $9 \%$ over the SV100 and fresh biomass in SVSi50 was increased 19 $\%$ over the SV50. The important thing is that despite the 50\% water saving in SVSub50 and SVSi50 compered with SV100, the amount of fresh biomass has decreased just $19 \%$ and $5 \%$ respectively. However the results show that the silicon fertilizer and subsurface irrigation can be used for irrigation management and water saving in field. In this way result showed the maximum actual root water uptake was happened in SVSub100 and SVSi100 treatments. Root Length Density 
RLD was measured four times during the experiment (Figure 3). On day 44, RLD was lower for control S100, SV100 and SVSub50 (7.6-10.15 g), when compared to the other treatments, which maintained a higher level of roots (13.65-15.55 g). This difference was again observed by the day 68. On day 89 however, treatment SV50 registered the lowest RLD (42.8 g), followed by the control S100 (48.65 g) and the two other water limited treatments (55.65 g and $58.45 \mathrm{~g}$ ). Finally, on day 101, the differences between treatments were more visible. Control S100 registered the lowest RLD values $(69.05 \mathrm{~g})$. The water limited treatments (50\% irrigation) resulted lower RLD values when compared to the $100 \%$ irrigation. However, RLD in SV50 was lower than when sub-surface irrigation and silicon fertilization was used (SV50 =67.75 g; SVSub50=81.95 g; SVSi50=90.75 g). Within the non-water limitation treatments the same effect was observed in the treatments, with silicon fertilization being the most responsive treatment $(\mathrm{SVSi100}=106.5 \mathrm{~g})$.

\subsection{Hydrus simulation results}

\subsubsection{Soil water content and root parameters validation}

The recorded soil water content was used to validate the model, since measurements undertaken in the greenhouse experiment were compared to soil water content simulated in Hydrus (Table 2). Results show that RMSE was higher in average in treatments SVSi50 and SVSub50, when compare to others including the lower values obtained in SV100. The reason for this discrepancy is based on the variability encountered between observed and modeled data taken in days before and after irrigation, which was present in all treatments, with the exception of SVSi50 where RMSE calculated was similar in all situations. The result of RMSE was obtained between 0.011-0.045 and agree with references (Vrugt et al., 2001, Kandelous and Šimůnek, 2010; Ursulino et al, 2019). The model efficiency (EF) was generally good, with values close to 1 in many treatments and agree with references (Homaee et al, 2002; Ursulino et al, 2019), with the exception of treatment SVSi100 where calculated EF was close to -0.290.20 in two different days.

When observing the RMSE calculated from the model validation using the RLD it is possible to see that the lower values were registered in S100, SV100 and SV50 treatments (Table 3). However, the RMSE were overall low, resulting in a good agreement between observed and simulated values. The same happened to the error calculated values.

\subsubsection{Root Water Uptake}

Root water uptake simulated in two dimensions (Figure 4) for each treatment in one season shows that Control S100 and the two limited water treatments SV50 and SVSub50 maintained low values within the profile $\left(<200 \mathrm{day}^{-1}\right)$. Contrarily, all treatments without water limitation and the treatment where 
1 silicon fertilization was used to overcome this limitation reached higher values up to 260 day $^{-1}$, 2 suggesting that enough water was supplied to maize in these cases. There was however some difference 3 in the depth where the highest uptake was taken place. While SV100, SVSi100 and SVSi50 all showed 4 higher root water uptake in the first layer of the in depth pot $(0-15 \mathrm{~cm})$ and horizontally $(0-10 \mathrm{~cm})$, the 5 SVSub100 treatment showed a root water uptake pattern with high values between 25 and $45 \mathrm{~cm}$ in 6 depth.

\subsubsection{Water balance}

\section{Discussion}

\subsection{Hydrus validation}

In general, the simulation of HYDRUS-2D software is well-matched with measurements, both in soil water content and root length density. RMSE and EF results for soil water content in the present study are in line with results from other studies where models were also used to simulate the water movement in soil (D'haeze et al., 2003; Homaee et al., 2002; Karandish and Shahnazari, 2016; Mapfumo et al., 2006; Mohanty et al., 2012; Ursulino et al, 2019)). Variations of soil water content between observed and simulated data are normal before irrigation due to a severe drop in moisture. Also, after irrigation the model may have trouble in adjusting to this disruptive event. In our results this was especially true one day after irrigation. Although this variation was observed in all treatments, the pots where silicon fertilizer were added registered the lower RMSE in average considering day before irrigation and up to 2 days after irrigation (Table 3). This well adjustment of the model might suggest that under these treatments (with or without water stress), the soil water content variation was smoother along the time. 
The root density modeled in Hydrus uses the description from (Vrugt et al., 2001). In this approach the root growth is introduced separately in different growth periods by the user as an input. Therefore, precise information about the root growing parameters along the simulation period is necessary to correctly assess the effects of different treatments in the water use and water uptake by the plant, such as studied here. The root length density assessed here by cutting the pots at four different moments is therefore an asset to assure good model results (Table 3).

Overall, the good agreement between data and model allowed us to further use the model to evaluate other flows that are not easily measured.

\subsection{Sub-surface irrigation and silicon fertilization effects in maize root water uptake}

In this work we have tested the sub-surface irrigation and the silicon-based fertilizer effects in maize root growth and root water uptake both in normal and water stress situations. The results show that when maize was subjected to water limitation (treatment 50\%), the root density increased by using subsurface irrigation and silicon fertilization. In fact, the increment by the end of the experiment (on day 101), was up to $21 \%$ and $34 \%$ respectively, when compared to the control SV50 treatment. This highlights that both subsurface irrigation and silicon fertilization have stimulated the development of the root system (Rizwan et al., 2015). Interestingly, results also showed that this effect was maintained when there was no water stress situation, although in a lower scale (2\% and $11 \%$ for subsurface irrigation and silicon fertilization). This outcome suggests that silicon uptake by plants has beneficial effects on the root development when this element is available in the soil matrix, and its effects go beyond the stress amelioration, like previously suggested (Artyszak et al., 2016; Lavinsky et al., 2016). The uptake of Si by maize improves root water uptake potential also in regular situations, standing as a more sustainable water management strategy for farmers. Such effect is also observed in the root water uptake flows simulated in Hydrus. At 100\% water supply, both silicon fertilization and sub-surface irrigation provide higher root water uptake in a larger area compared to control treatments. In the case of sub-surface irrigation it provided a more precise area of available water, since its maximum occurs at $30 \mathrm{~cm}$ where roots are normally displaced. However silicon fertilization is the only treatment able to increase root water uptake of roots up to higher than 200 day $^{-1}$ in water stress situations.

\subsection{Future implementations}

Sub-surface irrigation and silicon fertilization resulted in higher root water uptakes by maize with or without water stress situations (Figure 5) and so, we conclude that both as important options for farmers dealing with water limitation when growing crops, especially in semi-arid regions. However, the choice between one technique and another depends on many other factors that are beyond the analysis of this 
study. To summarize the advantages and disadvantages of both silicon fertilization and sub-surface irrigation, we have conducted a small SWOT analysis shown in Table 4 where strengths, weaknesses, opportunities and threats are listed for each option.

Sub-surface irrigation technology is based on the fact that water provided to the plant is directly inserted at the rhizosphere, maximizing the water use efficiency by decreasing losses along the way when compared to a traditional irrigation system where water is deposited at the soil surface and the pours into the sub-soil (Barão et al., 2010; Ward et al., 2012). Besides decreasing runoff and evaporation, subsurface irrigation also avoids water losses through the soil profile. On the other hand, to successfully implement this solution, it is required to dig the soil in order to insert the pipes for the sub-surface irrigation. This implementation disturbs the soil and promote an homogenization of the soil properties (Heidarpour et al., 2007), while potentially also contributing for $\mathrm{CO}_{2}$ emission through quick decomposition of organic matter, in a similar way of tillage operations (Panagos et al., 2015). Additionally this operation might lead to soil losses through erosion, especially in semi-arid regions where soil quality is already compromised (Barão et al., 2019).

Silicon fertilization has many strengths since it allows not only maize to grow under water limitation, but also ensures higher production even when water is not limiting the system, which represents an extra yield for the farmer. Additionally, several other benefits have been attributed to silicon effect in Si-accumulator crops such as maize, especially concerning the adaptation of crops in many other stressful and toxic situations, thus potentiating the overall crop performance (Datnoff et al., 2001; Keeping and Reynolds, 2009). Overall, this technique is less invasive compared to the sub-surface irrigation and does not produce extra residues, such as the pipes for the irrigation system. However, it is important to highlight that the production and transportation of silicon fertilization has itself an associated environmental impact that is unknown. In fact, the fertilizer production involves water and energy consumption and only a detailed life cycle assessment can determine the extend of these impacts (Barão and Teixeira, 2016). Also adding a source of silicon in soil will disturb the local chemicalphysical soil properties, with unexpected consequences.

In conclusion, these two techniques are valuable options for growing maize in water limitation. Farmers will also have to take into account their specific situation and evaluate their soil vulnerability to threats (Bünemann et al., 2018) such as erosion, salinization or soil organic matter losses and the agricultural management practices selected by the farmer (Barão et al., 2019).

\section{Conclusion}

The drastic reduction of freshwater resources due to agricultural activities remain nowadays as one the most challenging problems. While freshwater is necessary for human life, the food production is also 
essential for a population that is growing at a galloping rate. In this context, growing crops with high energetic and economic value with less water consumption without losing productivity is necessary to ensure the sustainable future development of humankind, especially in semi-arid regions. In this work, we have tested two options for growing maize in normal and water stress conditions: sub-surface irrigation and silicon fertilization. Results showed that both tested options resulted in an increase of the root system when water was limited (21\% and $34 \%$ for sub-surface irrigation and silicon fertilization respectively). Interestingly, when no limitation was induced, the silicon fertilization still showed an increase of $11 \%$ on the root system, showing that this effect goes beyond the limitation situation. Moreover, the simulation with Hydrus showed that both treatments also increase root water uptake. While sub-surface irrigation potentiates the higher uptake in the localized area of the rhizosphere, which is better for the general efficiency of the crop uptake, silicon fertilization is the only option able to increase the uptake up to more than $200 \mathrm{~L}$ in a water stressful situation. This study show that both solutions are viable to diminish the water consumption when growing crop, but future studies should evaluate also their secondary effects in soil quality, other crop types and their overall environmental impacts.

\section{Acknowledgements}

This research was supported by funds from the Urmia University and University of Lisbon.

\section{References}

Adrees, M., Ali, S., Rizwan, M., Zia-ur-Rehman, M., Ibrahim, M., Abbas, F., Farid, M., Qayyum, M.F., Irshad, M.K., 2015. Mechanisms of silicon-mediated alleviation of heavy metal toxicity in plants: A review. Ecotoxicol. Environ. Saf. 119, 186-197.

Arnell, N.W., 1999. Climate change and global water resources. Glob. Environ. Chang. 9, 31-49.

Artyszak, A., Gozdowski, D., Kucińska, K., 2016. The Effect of Calcium and Silicon Foliar Fertilization in Sugar Beet. Sugar Tech 18, 109-114.

Ayars, J.E., Phene, C.J., Hutmacher, R.B., Davis, K.R., Schoneman, R.A., Vail, S.S., Mead, R.M., 1999. Subsurface drip irrigation of row crops : a review of 15 years of research at the Water Management 42, 1-27.

Barão, L., Alaoui, A., Ferreira, C., Basch, G., Schwilch, G., Geissen, V., Sukkel, W., Lemesle, J., Garcia-Orenes, F., Morugán-Coronado, A., Mataix-Solera, J., Kosmas, C., Glavan, M., Pintar, 
M., Tóth, B., Hermann, T., Vizitiu, O.P., Lipiec, J., Reintam, E., Xu, M., Di, J., Fan, H., Wang, F., 2019. Assessment of promising agricultural management practices. Sci. Total Environ. 649, 610-619.

Barão, L., Chambel Leitão, P., Braunschweig, F., Neves, R.J., Gonçalves, M.C., Ramos, T.B., Castanheira, N.L., 2010. Simulation of water dynamics in two irrigated soils. Rev. CIÊNCIAS AGRÁRIAS 346-357.

Barão, L., Teixeira, R., 2016. The environmental impacts of silicon as an alternative to phosphorus fertilizers. Proceeding LCA Food 2016 Conf.

Boretti, A., Rosa L., 2019. Reassessing the projections of the World Water Development, npj Clean Water. 2:15Bünemann, E.K., Bongiorno, G., Bai, Z., Creamer, R.E., De Deyn, G., de Goede, R., Fleskens, L., Geissen, V., Kuyper, T.W., Mäder, P., Pulleman, M., Sukkel, W., van Groenigen, J.W., Brussaard, L., 2018. Soil quality - A critical review. Soil Biol. Biochem. 120, 105-125.

Craswell, E., Bonell, M., Bossio, D., Demuth, S., Giesen, N. van de, 2007. Integrated Assessment of Water Resources and Global Change. Book-Springer-Water Resources Management, 21(1).

Crusciol, C.A.C., Pulz, A.L., Lemos, L.B., Soratto, R.P., Lima, G.P.P., 2009. Effects of silicon and drought stress on tuber yield and leaf biochemical characteristics in potato. Crop Sci. 49, 949954.

D’haeze, D., Deckers, J., Raes, D., Phong, T.A., Chanh, N.D.M., 2003. Over-irrigation of Coffea canephora in the Central Highlands of Vietnam revisited: Simulation of soil moisture dynamics in Rhodic Ferralsols. Agric. Water Manag. 63, 185-202.

Darzi-Naftchali, A., Shahnazari, A., 2014. Influence of subsurface drainage on the productivity of poorly drained paddy fields. Eur. J. Agron. 56, 1-8.

Datnoff, L.E., Snyder, G.H., Korndörfer, G.H., 2001. Silicon in Agriculture, Elsevier.

Dry, P.R., Loveys, B.R., 1998. Factors influencing grapevine vigour and the potential for control with partial rootzone drying. Aust. J. Grape Wine Res. 4, 140-148.

Feddes, R.D., Hoff, H., Bruen, M., Dawson, T., de Rosnay, P., Dirmeyer, P., Jackson, R.B., Kabat, P., Kleidon, A., Lilly, A., Pitman, A.J., 2001. Modeling Root Water Uptake Reinder in Hydrological and Climate Models Modeling Root Water Uptake. Bull. Am. Meteorol. Soci. 
1 Gärdenäs, A.I., Hopmans, J.W., Hanson, B.R., Šimůnek, J., 2005. Two-dimensional modeling of nitrate leaching for various fertigation scenarios under micro-irrigation. Agric. Water Manag. 74, 219242.

Geerts, S., Raes, D., 2009. Deficit irrigation as an on-farm strategy to maximize crop water productivity in dry areas. Agric. Water Manag. 96, 1275-1284.

Gong, D., Kang, S., Zhang, L., Du, T., Yao, L., 2006. A two-dimensional model of root water uptake for single apple trees and its verification with sap flow and soil water content measurements. Agric. Water Manag. 83, 119-129.

Guntzer, F., Keller, C., Meunier, J.-D., 2011. Benefits of plant silicon for crops: a review. Agron. Sustain. Dev. 32, 201-213.

Han, M., Zhao, C., Feng, G., Yan, Y., Sheng, Y., 2015. Evaluating the effects of mulch and irrigation amount on soil water distribution and root zone water balance using HYDRUS-2D. Water (Switzerland) 7, 2622-2640.

Hanson, B.R., Šimůnek, J., Hopmans, J.W., 2006. Evaluation of urea-ammonium-nitrate fertigation with drip irrigation using numerical modeling. Agric. Water Manag. 86, 102-113.

Hattori, T., Inanaga, S., Araki, H., An, P., Morita, S., Luxova, M., Lux, A., 2005. Application of silicon enhanced drought tolerance in Sorghum bicolor. Physiol. Plant. 123, 459-466.

Heidarpour, M., Mostafazadeh-Fard, B., Koupai, J.A., Malekian, R., 2007. The effect of municipal effluent using pressure and surface irrigation methods on selected soil chemical properties in an arid region. Agrochimica. 51, 329-337.

Hodson, M.J., White, P.J., Mead, a, Broadley, M.R., 2005. Phylogenetic variation in the silicon composition of plants. Ann. Bot. 96, 1027-46.

Hoekstra, A.Y., Mekonnen, M.M., 2012. The water footprint of humanity. Cancer Res. 109, 32323237.

Homaee, M., Dirksen, C., Feddes, R.A., 2002. Simulation of root water uptake I. Non-uniform transient salinity using different macroscopic reduction functions. Agric. Water Manag. 57, 89-109. 
Kandelous, M.M, Simunek, J., M. van Genuchten, M.T, Malek, K., 2011. Soil Water Content Distributions between Two Emitters of a Subsurface Drip Irrigation System, Soil Sci. Soc. Am. J. 75:488-497.

Kandelous, M.M., Šimůnek, J., 2010. Numerical simulations of water movement in a subsurface drip irrigation system under field and laboratory conditions using HYDRUS-2D. Agric. Water Manag. 97, 1070-1076.

Kang, S., Zhang, J., 2004. Controlled alternate partial root-zone irrigation: Its physiological consequences and impact on water use efficiency. J. Exp. Bot. 55, 2437-2446.

Kanga, Sh., Lianga, Z., Panb, Y., Shic, P., Zhangd, J. 2000. Alternate furrow irrigation for maize production in an arid area, Agric. Water Manag. 45, 267-274

Karandish, F., Shahnazari, A., 2016. Soil Temperature and Maize Nitrogen Uptake Improvement Under Partial Root-Zone Drying Irrigation. Pedosphere 26, 872-886.

Karandish, F., Simunek, J. 2016. A comparison of numerical and machine-learning modeling of soil water content with limited input data. Journal of Hydrology, 543, 892-909.

Keeping, M.G., Reynolds, O.L., 2009. Silicon in agriculture: New insights, new significance and growing application. Ann. Appl. Biol. 155, 153-154.

Kresovi'ca B, Tapanarovab A, Zorica Tomi’cb, Ljubomir ${ }^{` Z}$ Zivoti’́cb,Dragan Vujovi'cb, Zorica Sredojevi'cb, Bo`sko Gaji'cb, 2016. Grain yield and water use efficiency of maize as influenced bydifferent irrigation regimes through sprinkler irrigation undertemperate climateBranka, Agric. Water Manag. 16934-43

Kresović, B., Gajić, B., Tapanarova, A., Dugalić G. 2018. How Irrigation Water Affects the Yield and Nutritional Quality of Maize (Zea mays L.) in a Temperate Climate, Pol. J. Environ. Stud. 27, 3:1123-1131.

Lavinsky, A.O., Detmann, K.C., Reis, J. V., Ávila, R.T., Sanglard, M.L., Pereira, L.F., Sanglard, L.M.V.P., Rodrigues, F.A., Araújo, W.L., DaMatta, F.M., 2016. Silicon improves rice grain yield and photosynthesis specifically when supplied during the reproductive growth stage. J. Plant Physiol. 206, 125-132. Li, X., Shi, H., Šimůnek, J., Gong, X., Peng, Z., 2015. Modeling soil water dynamics in a drip-irrigated intercropping field under plastic mulch. Irrig. Sci. 33, 289302. 
Mapfumo, E., Chanasyk, D.S., Chaikowsky, C.L.A., 2006. Simulation of soil water content on a small reclaimed watershed in northern Alberta using the Root Zone Water Quality Model (RZQWM). Can. J. Soil Sci. 86, 675-690.

Milly, P.C.D., Dunne, K.A., Vecchia, A. V., 2005. Global pattern of trends in streamflow and water availability in a changing climate. Nature $438,347-350$.

Mohammadi, A., Besharat, S., Abbasi, F., 2019. Effects of irrigation and fertilization management on reducing nitrogen losses and increasing corn yield under furrow irrigation. Agric. Water Manag. $213,1116-1129$.

Mohanty, M., Probert, M.E., Reddy, K.S., Dalal, R.C., Mishra, A.K., Subba Rao, A., Singh, M., Menzies, N.W., 2012. Simulating soybean-wheat cropping system: APSIM model parameterization and validation. Agric. Ecosyst. Environ. 152, 68-78.

Oki, T., Kanae S., 2006. Global Hydrological Cycles and World Water Resources. Science. 313, 10681072.

Panagos, P., Borrelli, P., Meusburger, K., Alewell, C., Lugato, E., Montanarella, L., 2015. Estimating the soil erosion cover-management factor at the European scale. Land use policy 48, 38-50.

Payero, J.O., Melvin, S.R., Irmak, S., Tarkalson, D., 2006. Yield response of corn to deficit irrigation in a semiarid climate. Agric. Water Manag. 84, 101-112.

Pimentel, D., Harvey, C., Resosudarmo, P., Sinclair, K., Kurz, D., McNair, M., Crist, S., Shpritz, L., Fitton, L., R., S., Blair, R., 1995. Environmental and Economic Costs of Soil Erosion and Conservation Benefits. Science (80-. ). 267, 1117-1123.

Ragab, R., Prudhomme, C., 2002. Climate change and water resources management in arid and semiarid regions: Prospective and challenges for the 21st century. Biosyst. Eng. 81, 3-34.

Rizwan, M., Ali, S., Ibrahim, M., Farid, M., Adrees, M., Bharwana, S.A., Zia-ur-Rehman, M., Qayyum, M.F., Abbas, F., 2015. Mechanisms of silicon-mediated alleviation of drought and salt stress in plants: a review. Environ. Sci. Pollut. Res. 22, 15416-15431.

Rodgers-Gray, B.S., Shaw, M.W., 2004. Effects of straw and silicon soil amendments on some foliar and stem-base diseases in pot-grown winter wheat. Plant Pathol. 53, 733-740. 
Saud, S., Li, X., Chen, Y., Zhang, L., Fahad, S., Hussain, S., Sadiq, A., Chen, Y., 2014. Silicon application increases drought tolerance of Kentucky bluegrass by improving plant water relations and morphophysiological functions. Sci. World J. 2014.

Schaap, M.G., 2002. Rosetta v1.2: A computer program for estimating soil hydraulic parameters with hierarchical pedotransfer functions $251,163-176$.

Schaetzl, R.J., Anderson, S., 2005. Soils Genesis And Geomorphology. Cambridge University Press, New York.

Shao, G.C., Zhang, Z.Y., Liu, N., Yu, S.E., Xing, W.G., 2008. Comparative effects of deficit irrigation (DI) and partial rootzone drying (PRD) on soil water distribution, water use, growth and yield in greenhouse grown hot pepper. Sci. Hortic. (Amsterdam). 119, 11-16.

Siyal, A.A., Skaggs, T.H., 2009. Measured and simulated soil wetting patterns under porous clay pipe sub-surface irrigation. Agric. Water Manag. 96, 893-904.

Ursulino, B. S., Montenegro, S. M. G. L., Coutinho, A. P., Coelho, V. H. R., dos Santos Araújo, D. C., Gusmão, A. C. V., dos Santos Neto, S. M., Lassabatere, L., Angulo-Jaramillo, R. 2019. Modelling soil water dynamics from soil hydraulic parameters estimated by an alternative method in a tropical experimental basin, Water, 11(5), 1007.

Van Dam, J.C., Feddes, R.A., 2000. Numerical simulation of infiltration, evaporation and shallow groundwater levels with the Richards equation. J. Hydrol. 233, 72-85.

Van Genuchten, M.T., 1980. A Closed-form Equation for Predicting the Hydraulic Conductivity of Unsaturated Soils 1. Soil Sci. Soc. Am. J. 44, 892-898.Vrugt, J.A., Hopmans, J.W., Simunek, J., 2001. Calibration of a Two-Dimensional Root Water Uptake Model. Soil Sci. Soc. Am. 65, 1027-1037.

Ward, P.R., Flower, K.C., Cordingley, N., Weeks, C., Micin, S.F., 2012. Soil water balance with cover crops and conservation agriculture in a Mediterranean climate. F. Crop. Res. 132, 33-39. 


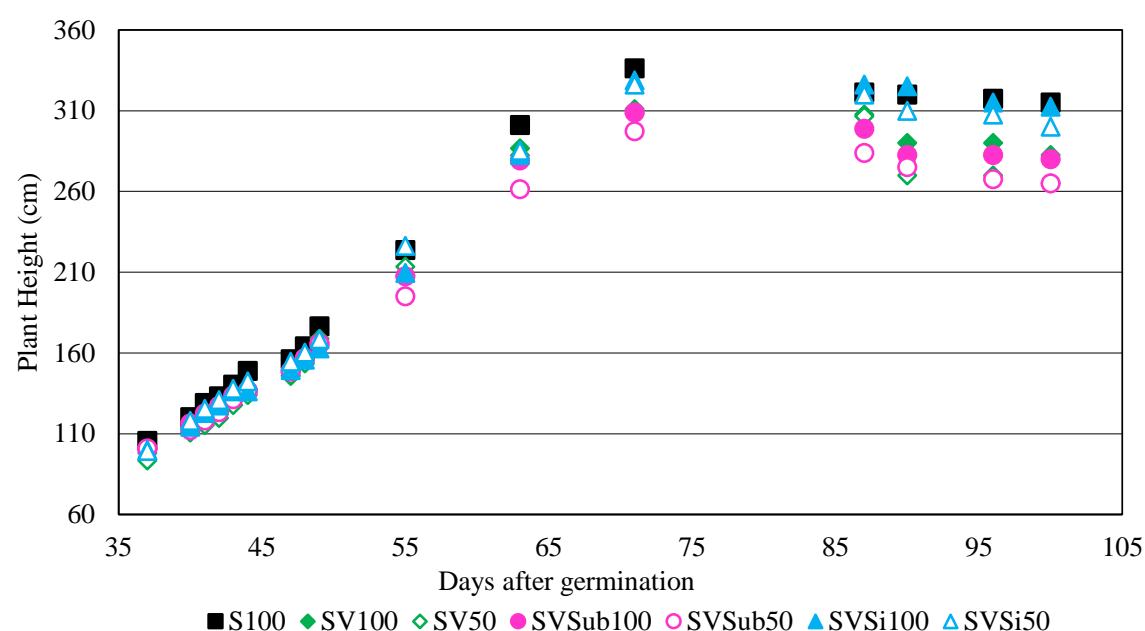

3

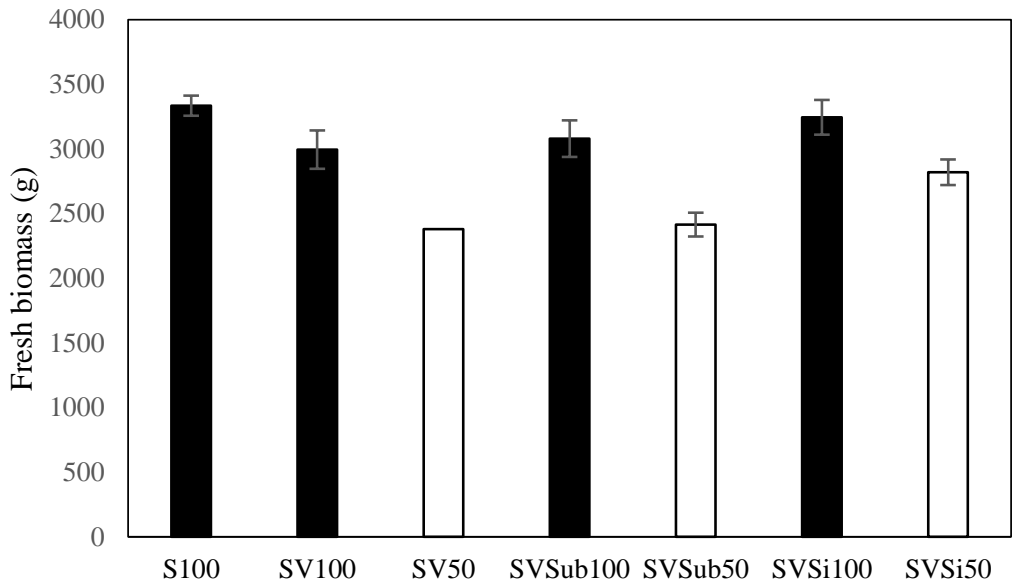

Figure 1 - Plant height $(\mathrm{cm})$ measured in each treatment at different moments. The number of replicates changed along the time. 


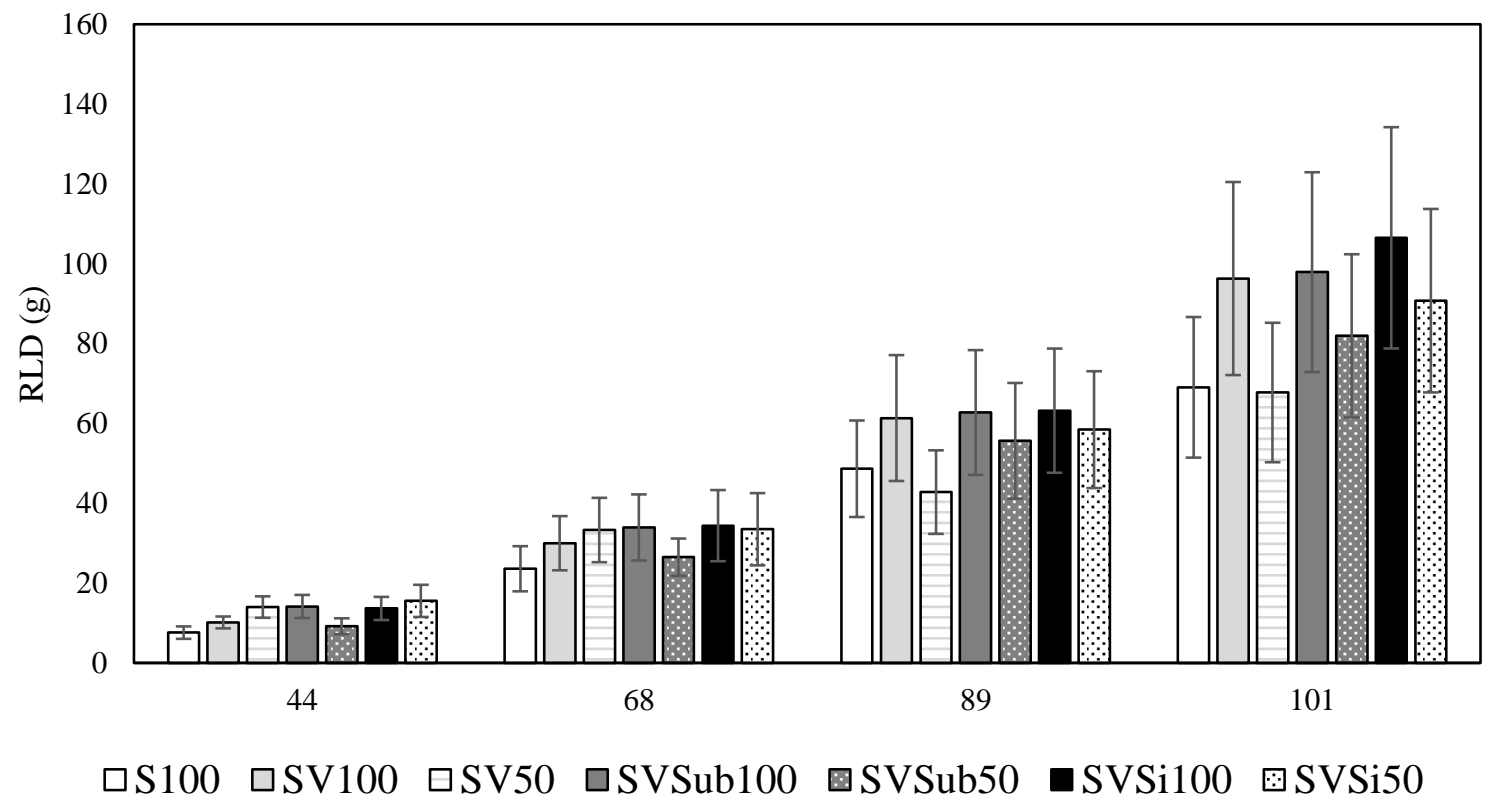

1 Figure 3 - Root Length Density (RDL) measured (g) for each treatment 

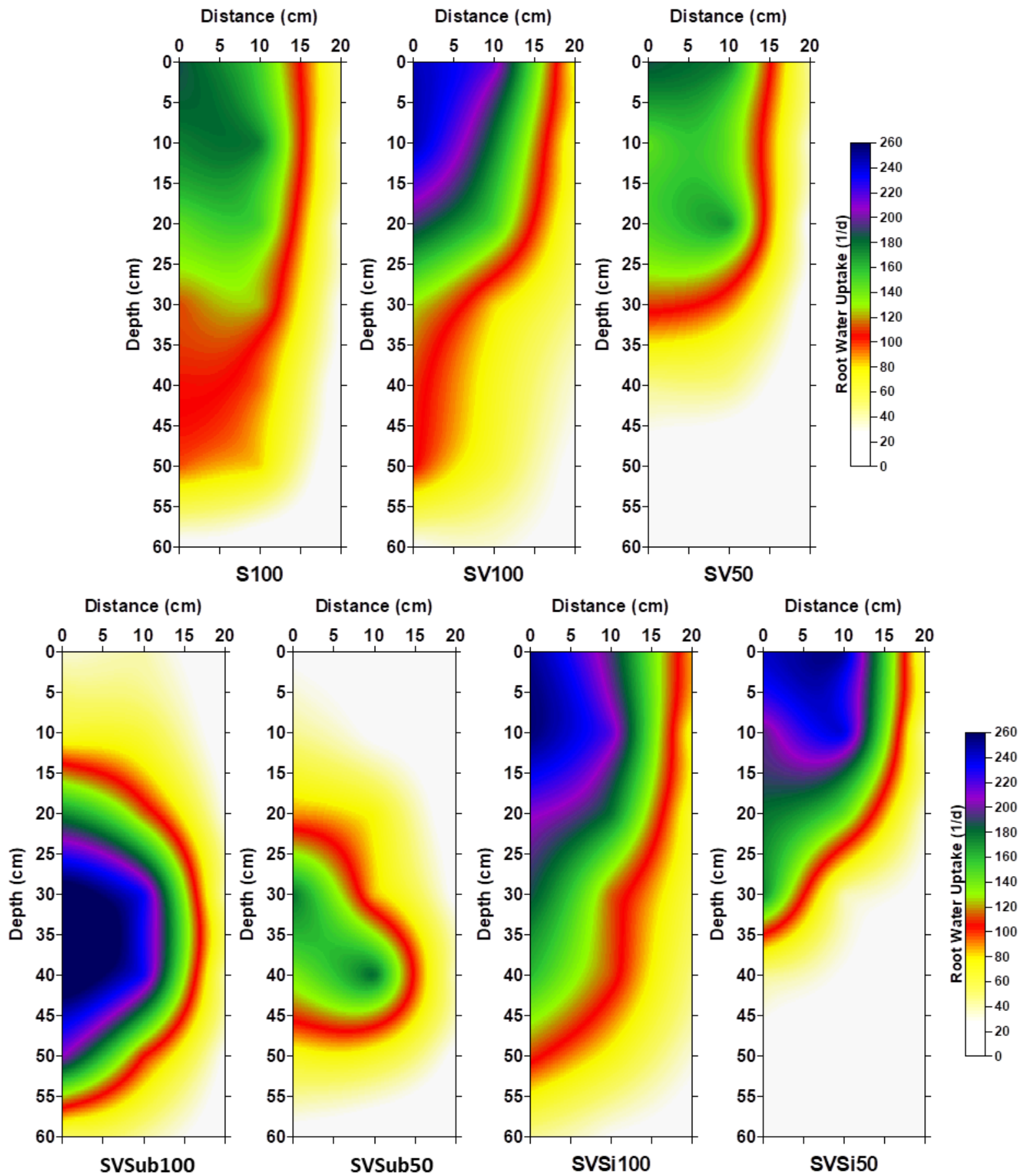

Figure 4 - Root water uptake $\left(\right.$ day $\left.^{-1}\right)$ of maize in the treatments during the complete growing stage calculated in Hydrus in 2D. 


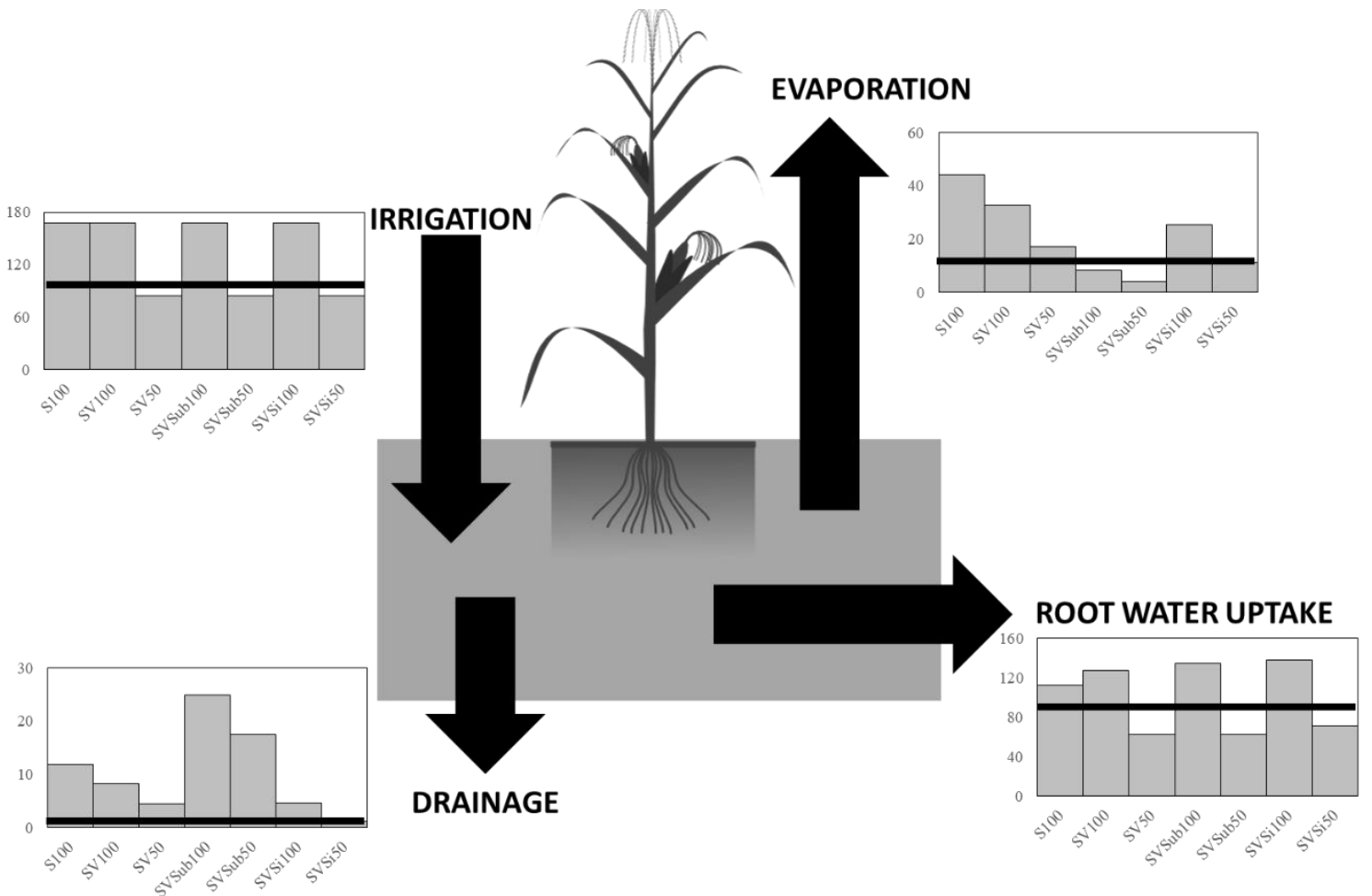

Figure 5 - Water balance calculated for each treatment: Irrigation, evaporation, transpiration and drainage volumes (L). Black lines represent the in and out flows of water.

Table 1 - Physical properties of the soil collected and vermiculite, used in the greenhouse experiment, namely texture, particle size distribution (\%), bulk density $\left(\mathrm{kg} \mathrm{m}^{-3}\right)$ and field capacity $\left(\mathrm{cm}^{3} \mathrm{~cm}^{-3}\right)$.

\begin{tabular}{|c|c|c|c|c|c|c|}
\hline \multirow{2}{*}{ Type } & \multirow{2}{*}{ Texture } & \multicolumn{3}{|c|}{ Particle Size Distribution (\%) } & \multirow{2}{*}{$\begin{array}{c}\text { Bulk } \\
\text { Density } \\
\left(\text { kg m }^{-3}\right)\end{array}$} & \multirow{2}{*}{$\begin{array}{c}\text { Field } \\
\text { Capacity } \\
\left(\mathrm{cm}^{3} \mathrm{~cm}^{-3}\right)\end{array}$} \\
\hline & & $<0.002 \mathrm{~mm}$ & $0.02-0.002 \mathrm{~mm}$ & $2.0-0.02 \mathrm{~mm}$ & & \\
\hline & Loam & 8 & 60 & 32 & 1.57 & 0.27 \\
\hline Vermiculite & - & 4 & 22 & 74 & 1.82 & 0.32 \\
\hline
\end{tabular}

Table 2 - RSME and EF obtained for each treatment using the soil water content measured and predicted by the model. If all predicted and observed values were the same, the statistics would have values of RMSE= $0.0, \mathrm{EF}=1.0$.

\begin{tabular}{cccccccc}
\hline RSME $\left(\mathbf{c m}^{\mathbf{3}} \mathbf{~ c m}^{-\mathbf{3}}\right)$ & S100 & SV100 & SV50 & SVSub100 & SVSub50 & SVSi100 & SVSi50 \\
\hline Before irrigation & 0.016 & 0.013 & 0.014 & 0.033 & 0.018 & 0.014 & 0.045 \\
After irrigation & 0.024 & 0.022 & 0.022 & 0.024 & 0.032 & 0.024 & 0.042 \\
One day after irrigation & 0.022 & 0.014 & 0.024 & 0.017 & 0.031 & 0.011 & 0.028 \\
Two days after irrigation & 0.020 & 0.024 & 0.013 & 0.018 & 0.019 & 0.023 & 0.044 \\
\hline & & & & & & & \\
\hline EF (-) & S100 & SV100 & SV50 & SVSub100 & SVSub50 & SVSi100 & SVSi50 \\
\hline Before irrigation & 0.48 & 0.86 & 0.74 & 0.33 & 0.73 & 0.47 & 0.14 \\
After irrigation & 0.90 & 0.95 & 0.89 & 0.90 & 0.64 & 0.51 & 0.53 \\
One day after irrigation & 0.86 & 0.94 & 0.71 & 0.79 & 0.53 & 0.20 & 0.59 \\
Two days after irrigation & 0.37 & 0.73 & 0.36 & 0.54 & 0.55 & -0.29 & 0.22 \\
\hline
\end{tabular}


Table 3 - Optimized root density parameters for each treatment and corresponding Error and RMSE comparing the observed and the simulated values.

\begin{tabular}{cccccccc}
\hline & S100 & SV100 & SV50 & SuSV100 & SuSV50 & SVSi100 & SVSi50 \\
\hline Px & 4.82 & 3.47 & 3.59 & 4.43 & 4.97 & 3.19 & 3.45 \\
$\mathrm{X}^{*}$ & 3.48 & 0.79 & 2.68 & 2.13 & 2.11 & 1.89 & 2.24 \\
$\mathrm{Pz}$ & 1.62 & 1.57 & 1.87 & 0.30 & 0.17 & 0.64 & 0.89 \\
$\mathrm{Z}^{*}$ & 0.01 & 1.92 & 0.56 & 0.09 & 0.43 & 0.02 & 0.05 \\
Error & 12.47 & 7.00 & 7.68 & 14.12 & 11.28 & 14.84 & 11.35 \\
RMSE & 0.15 & 0.20 & 0.16 & 0.34 & 0.27 & 0.33 & 0.28 \\
\hline
\end{tabular}

Table 4 - SWOT analysis for silicon fertilization and sub-surface irrigation for semi-arid regions.

\begin{tabular}{|c|c|c|c|}
\hline $\begin{array}{c}\text { Silicon } \\
\text { Fertilization } \\
\end{array}$ & $\begin{array}{c}\text { Sub-surface } \\
\text { Irrigation }\end{array}$ & $\begin{array}{c}\text { Silicon } \\
\text { Fertilization }\end{array}$ & $\begin{array}{c}\text { Sub-surface } \\
\text { Irrigation }\end{array}$ \\
\hline \multicolumn{2}{|c|}{ Strength } & \multicolumn{2}{|c|}{ Weakness } \\
\hline $\begin{array}{l}\text { - Not invasive } \\
\text { (applied as } \\
\text { fertilizer); } \\
\text { - Increases RLD } \\
\text { even when no } \\
\text { stress is present; }\end{array}$ & $\begin{array}{l}\text { - Decreases losses per } \\
\text { evaporation, water } \\
\text { is provided directly } \\
\text { in the rhizosphere; }\end{array}$ & $\begin{array}{l}\text { Extra cost for } \\
\text { farmers; }\end{array}$ & $\begin{array}{c}\text { - Invasive } \\
\text { technique; } \\
\text { - Extra cost for } \\
\text { farmers; } \\
\text { - Tubes are } \\
\text { extra residues }\end{array}$ \\
\hline \multicolumn{2}{|c|}{ Opportunity } & \multicolumn{2}{|c|}{ Threat } \\
\hline $\begin{array}{l}\text { - Growing crops in } \\
\text { water limitation } \\
\text { situations; } \\
\text { - Possibility to } \\
\text { grow crops in } \\
\text { other limitations } \\
\text { and toxicities; }\end{array}$ & $\begin{array}{l}\text { - Growing crops in } \\
\text { water limitation } \\
\text { situations; }\end{array}$ & $\begin{array}{l}\text { - The total } \\
\text { environmental } \\
\text { impact is } \\
\text { unknown and } \\
\text { has to be taken } \\
\text { into account; } \\
\text { - The unknown } \\
\text { effect of Si } \\
\text { availability in } \\
\text { local soil } \\
\text { biogeochemistry; }\end{array}$ & $\begin{array}{l}\text { - Susceptibility } \\
\text { to soil erosion, } \\
\text { organic matter } \\
\text { losses, } \mathrm{CO}_{2} \\
\text { emission; }\end{array}$ \\
\hline
\end{tabular}

9 